CAETANO, G.A.O., CAETANO JÚNIOR, M.B. e ZMIESKI, E.C. Efeito da duração do período seco sobre a reprodução de vacas leiteiras durante a lactação subsequente. PUBVET, Londrina, V. 8, N. 15, Ed. 264, Art. 1753, Agosto, 2014.

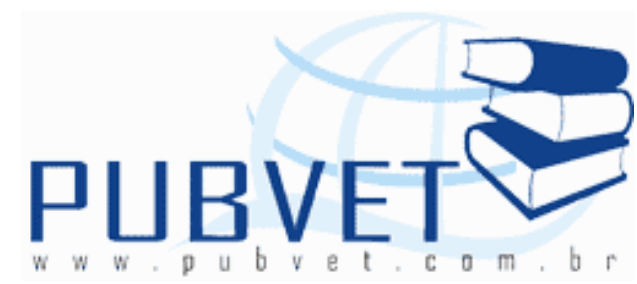

PUBVET, Publicações em Medicina Veterinária e Zootecnia.

\title{
Efeito da duração do período seco sobre a reprodução de vacas leiteiras durante a lactação subsequente
}

\author{
Graciele Araújo de Oliveira Caetano ${ }^{1}$, Messias Batista Caetano Júnior ${ }^{2}$ e \\ Elizângela de Carli Zmieski³
}

1 Zootecnista, Mestre em Produção Animal - UFVJM

2 Zootecnista - IFMG/Bambuí

3 Zootecnista - UFT

\section{Resumo}

Possíveis vantagens da redução da duração do período seco incluem aumento da renda oriunda da produção de leite, gerenciamento simplificado de vaca seca, diminuição dos distúrbios metabólicos e redução da superlotação de vacas secas nas instalações. Há dados abundantes para suportar um período de 60 dias de seca para maximizar a produção de leite da lactação seguinte. A grande maioria dos dados são de estudos utilizando registos de exploração. Nestes conjuntos de dados, as vacas com menos de 6 - 8 semanas períodos de seca, provavelmente não se destinavam a ter pequenos períodos de seca e, consequentemente não foram geridos por curtos períodos de seca. Além disso, as recomendações a partir de dados observacionais podem ser tendenciosos devido às interações, por exemplo, entre a produção de leite e duração do período de seca. Alguns experimentos delineados para comparar 30 e 60 dias de períodos de seca, indicam que os períodos secos mais curtos são possíveis 
CAETANO, G.A.O., CAETANO JÚNIOR, M.B. e ZMIESKI, E.C. Efeito da duração do período seco sobre a reprodução de vacas leiteiras durante a lactação subsequente. PUBVET, Londrina, V. 8, N. 15, Ed. 264, Art. 1753, Agosto, 2014.

sem sacrificar a produção de leite da lactação seguinte. Vários estudos indicam que a eliminação completa do período seco resulta em uma diminuição de 20 a $25 \%$ na produção de leite na lactação seguinte, no entanto, esses estudos têm utilizado o número pequeno de vacas e vacas com baixa produção de leite. São escassos os dados para determinar os efeitos do encurtamento do período de seca na composição do leite, na performance reprodutiva e na ocorrência de desordens metabólicas. Futuros estudos para aumentar o conhecimento dos fatores que afetam a proliferação das células mamárias e apoptose poderão produzir estratégias para reduzir a duração ou eliminar completamente o período seco.

Palavras-chave: Período seco, ovulação pós-parto, vacas leiteiras.

\title{
Effect of dry period on reproduction of dairy cows during subsequent lactation
}

\begin{abstract}
Possible advantages of reducing length of dry period include increased income from milk production, simplified dry cow management, decreased metabolic disorders, and alleviation of overcrowded dry cow facilities. There is abundant data to support a $60-\mathrm{d}$ dry period to maximize milk yield the next lactation. The great majority of data is from studies using farm records. In these data sets, cows with less than 6- to 8-wk dry periods probably were not intended to have short dry periods and consequently were not managed for short dry periods. Additionally, recommendations from observational data may be biased due to interactions, e.g., between milk yield and length of dry period. Some experiments specifically designed to compare 30- and 60-d dry periods indicate that shorter dry periods are possible without sacrificing milk production the next lactation. There is a paucity of data to determine the effects of shortening the dry period on milk composition, metabolic disorders, and reproductive performance. The limited amount of information that is available indicates that
\end{abstract}


CAETANO, G.A.O., CAETANO JÚNIOR, M.B. e ZMIESKI, E.C. Efeito da duração do período seco sobre a reprodução de vacas leiteiras durante a lactação subsequente. PUBVET, Londrina, V. 8, N. 15, Ed. 264, Art. 1753, Agosto, 2014.

shortening the dry period will probably not have negative effects on these parameters and may have slight beneficial effects. In some cases, the beneficial effects may have resulted, in part, due to negative effects on milk production. Cows with longer calving intervals and older cows may be more likely to avoid negative effects of shortening dry periods on subsequent milk yield. Shortening the dry period by initiating milking after a dry period but prior to parturition does not increase milk yield or improve animal health sufficiently to warrant consideration. Several studies indicated complete elimination of the dry period results in a 20 to $25 \%$ decrease in milk yield the following lactation. However, these studies have utilized low cow numbers and cows with extremely low milk production. As milk yield and persistency of lactation increases, either through genetic selection or administration of exogenous agents such as bST, the likelihood of successfully shortening or eliminating the dry period should increase. Future studies to increase our knowledge of factors affecting mammary epithelial cell proliferation and apoptosis should yield strategies to reduce the length or completely eliminate the dry period.

Keywords: Dry period, postpartum ovulation, dairy cows

\section{INTRODUÇÃO}

A pecuária leiteira no Brasil é caracterizada pela heterogeneidade entre os produtores que se classificam desde especializados, que produzem uma grande quantidade de leite, a sazonais, que fazem da pecuária leiteira uma fonte de renda complementar a agricultura ou à pecuária de corte. Existe uma predominância de pequenos produtores que participam de forma proporcional, com um menor volume no total de leite produzido no país.

Esta pecuária encontra-se em fase de transição, passando de um modelo extrativista a uma pecuária competitiva, tendo assim, que produzir de forma eficiente e com baixo custo. 
CAETANO, G.A.O., CAETANO JÚNIOR, M.B. e ZMIESKI, E.C. Efeito da duração do período seco sobre a reprodução de vacas leiteiras durante a lactação subsequente. PUBVET, Londrina, V. 8, N. 15, Ed. 264, Art. 1753, Agosto, 2014.

A eficiência reprodutiva é um dos principais fatores que influenciam a produtividade do rebanho leiteiro. Fatores nutricionais, sanitários e problemas na identificação do cio contribuem para atraso no retorno à atividade ovariana pós-parto, maior período de serviço e de intervalo entre parto, redução no período de lactação e menor produção de bezerros por ano e durante sua vida útil. Consequentemente, os custos de produção são elevados pela manutenção de animais com baixa produção no rebanho.

Para que sejam obtidos padrões ideais de eficiência reprodutiva, ou seja, a produção de uma cria/ano, com intervalo de parto de 12 a 12,5 meses e período de lactação de 10 meses, é imprescindível a ocorrência da perfeita interação dos parâmetros genéticos, reprodutivos, sanitários e nutricionais. Neste sentido, faz-se necessário a análise da performance reprodutiva animal, estabelecendo-se e avaliando-se parâmetros e índices reprodutivos, para que se possa identificar, definir metas, monitorar e solucionar os fatores que estão comprometendo a eficiência reprodutiva e produtiva do rebanho.

Avaliação do comprimento ideal de período seco tem sido baseado em produção de leite, mas a saúde animal e o desempenho reprodutivo podem ter conta na tomada desta decisão. Há uma pesquisa limitada sobre o efeito do comprimento do período seco sobre a reprodução. Tem-se especulado que o comprimento do período seco pode influenciar o equilíbrio energético no pósparto $(B E)$, alterando potencialmente o desempenho reprodutivo.

Existe uma relação entre o balanço energético e a primeira ovulação pósparto (BUTLER et al., 1981; CANFIELD et al., 1990). Butler et al. (1981) teorizou que o balanço energético foi importante para determinar a primeira ovulação pós-parto e retomada da ciclicidade. A primeira ovulação pós-parto ocorreu entre dez e quatorze dias após o balanço energético ser alcançado. Rastani et al. (2005) relataram que vacas que não recebem nenhuma secagem ou secagem reduzida (28 dias) tiveram balanço energético menos negativo em comparação com as vacas em um tradicional período de secagem. Coerente com a relação entre balanço energético e os dias de ovulação após o parto, 
CAETANO, G.A.O., CAETANO JÚNIOR, M.B. e ZMIESKI, E.C. Efeito da duração do período seco sobre a reprodução de vacas leiteiras durante a lactação subsequente. PUBVET, Londrina, V. 8, N. 15, Ed. 264, Art. 1753, Agosto, 2014.

Gümen et al. (2005) verificaram que vacas com menor período de secagem ovularam mais cedo $(13,2 ; 23,8$ e 31,9 dias para 0,28 e 56 dias de período seco, respectivamente).

O desempenho reprodutivo do gado leiteiro é melhorado com retorno mais precoce à ciclicidade (THATCHER \& WILCOX, 1973; DARWASH et al., 1997; STAPLES et al., 1990), no entanto, alguns estudos relataram menor (SMITH e WALLACE, 1998) ou nenhuma alteração (ROYAL et al., 2000) no desempenho reprodutivo com o menor tempo para a primeira ovulação. Coerente com o conceito de que antes da primeira ovulação pode melhorar o desempenho reprodutivo, diminuindo a duração da secagem foi associado com uma maior porcentagem de vacas prenhes na primeira IA (55, 26 e 20\% para 0,28 e 56 dias de período seco, respectivamente) e dias abertos diminuiu (94, 121 e 145 dias de 0, 28 e 56 dias de período seco), respectivamente (GUMEN et al., 2005).

No entanto, esses autores afirmaram que o seu estudo não foi feito com um número suficiente de vacas ( $\mathrm{n}=66$ em três grupos de tratamento) para permitir uma avaliação válida de comprimento de período de secagem sobre as importantes medidas econômicas de eficiência reprodutiva. Em outro estudo recente (PEZEHSKI et al., 2007), as medidas de reprodução foram alteradas pelo comprimento variável do período de secagem. Os dias abertos foi um pouco menor nas vacas com 56 dias de secagem do que com a 42 dias, mas o serviço de primeira taxa de concepção foi maior em multíparas com 35 dias PS. Ainda assim, a maioria das diferenças nas medidas de reprodução não alcançaram significância estatística devido à replicação inadequada ( $n=108$ vacas foram divididas em 3 grupos de tratamento). 
CAETANO, G.A.O., CAETANO JÚNIOR, M.B. e ZMIESKI, E.C. Efeito da duração do período seco sobre a reprodução de vacas leiteiras durante a lactação subsequente. PUBVET, Londrina, V. 8, N. 15, Ed. 264, Art. 1753, Agosto, 2014.

\section{REVISÃO DE LITERATURA}

\subsection{Principais hormônios relacionados à reprodução}

Os sistemas nervoso e endócrino são responsáveis pela integração do metabolismo entre diversos órgãos. O sistema nervoso age através de neurotrasmissores e o sistema endócrino age através de segundos mensageiros que são chamados de hormônios. Estes dois sistemas estão interligados, podendo o sistema nervoso agir no controle do sistema endócrino e vice-versa (GONZÁLEZ, 2002).

O sistema neuroendócrino está intimamente ligado aos processos metabólicos da nutrição, do crescimento e da reprodução, sendo a base do controle destes processos, (GONZÁLEZ, 2002), tendo a função de regular, estimular ou inibir as atividades funcionais de seus órgãos ou tecidos-alvos (HAFEZ, 2004). Os hormônios informam ao sistema nervoso sobre o status nutricional, condições reprodutivas, e em consequência promovem adequação, que são apropriadas para as condições ambientais, nutricionais e reprodutivas (SCHNEIDER, 2004). Os hormônios têm diferenças quanto a sua forma de síntese, armazenagem, meia-vida, forma de transporte e mecanismo de ação (GONZÁLEZ, 2002).

\subsubsection{Hormônio liberador de gonadotrofinas}

O hormônio liberador de gonadotrofinas (GnRH) é um hormônio protéico, formado por dez aminoácidos (decapeptídeos). Sua produção e armazenamento são feitos pelo hipotálamo. O GnRH fornece uma ligação humoral entre o sistema endócrino e nervoso, através do controle neuroendócrino. Os pulsos de GnRH são transportados pelos capilares-porta para as células da hipófise anterior promovendo a liberação das gonadotrofinas (hormônio luteinizante - LH, e hormônio folículo estimulante - FSH). 
CAETANO, G.A.O., CAETANO JÚNIOR, M.B. e ZMIESKI, E.C. Efeito da duração do período seco sobre a reprodução de vacas leiteiras durante a lactação subsequente. PUBVET, Londrina, V. 8, N. 15, Ed. 264, Art. 1753, Agosto, 2014.

Os neurônios do núcleo arqueado, núcleo ventro-medial e eminência média são centros de controle responsáveis por estimular a secreção tônica de FSH e LH. A área hipotalâmica anterior, os núcleos pré-ópticos e núcleo supraquiasmático são responsáveis por estimular a onda pré-ovulatória de FSH e LH. Através da retroalimentação positiva causada pelo aumento nas concentrações circulantes de estrógenos sobre o hipotálamo, ocorre uma onda repentina de $\mathrm{GnRH}$, acompanhada pela onda pré-ovulatória de $\mathrm{LH}$ e FSH. (HAFEZ, 2004). Pulsos mais freqüentes de GnRH favorecem a secreção de LH e pulsos mais esparsos favorecem a secreção de FSH (MEDEIROS \& MEDEIROS, 2006).

A liberação de GnRH sofre um bloqueio parcial pelas gonadotrofinas que atingem o hipotálamo pelo vaso de fluxo retrógrado, que é um mecanismo também conhecido por "feed back" negativo, que permite às gonadotrofinas hipofisárias influenciarem a atividade secretrória do GnRH sem a mediação das gônadas. A progesterona, quando permanece em níveis elevados na circulação, também é responsável por bloquear a liberação de GnRH, LH e FSH (ANTONIOLLI, 2002), através do mecanismo de retroalimentação de alça longa, que envolve interação entre a gônada, a hipófise e o hipotálamo (HAFEZ, 2004).

\subsubsection{Hormônio Folículo Estimulante}

O hormônio folículo estimulante (FSH) é um hormônio glicoprotéico, produzido pelas células gonadotrofos na hipófise anterior. Através da circulação, esta gonadotrofina chega aos ovários, onde será o principal hormônio no controle do crescimento folicular (GONZÁLEZ, 2002; HAFEZ, 2004).

Segundo estudos de Gong et al. (1996), os folículos bovinos crescem até os $4 \mathrm{~mm}$ de diâmetro na ausência de FSH e LH, dependendo de fatores ovarianos intrínsecos. Já entre 4 e $8 \mathrm{~mm}$, o folículo mostrou-se depende de FSH 
CAETANO, G.A.O., CAETANO JÚNIOR, M.B. e ZMIESKI, E.C. Efeito da duração do período seco sobre a reprodução de vacas leiteiras durante a lactação subsequente. PUBVET, Londrina, V. 8, N. 15, Ed. 264, Art. 1753, Agosto, 2014.

e independente de $\mathrm{LH}$, e os maiores que $9 \mathrm{~mm}$ só foram observados na presença de LH.

Quando as concentrações de FSH circulantes aumentam periodicamente, agem na emergência das ondas foliculares. De acordo com o crescimento dos folículos, a produção de estrógeno e inibina vão aumentando, fazendo uma retroalimentação negativa para o FSH (GIBBONS et al., 1997).Com as concentrações de FSH diminuídas, ocorre uma limitação no crescimento folicular, levando a maioria dos folículos recrutados entrarem em atresia (BINELLI, IBIAPINA \& BISINOTTO, 2006). Neste momento o folículo dominante passa a ser dependente de $\mathrm{LH}$, já que as células da granulosa já adquiriram receptores para LH perto do momento da seleção do folículo dominante (WEBB et al., 2003).

A secreção de FSH pelos gonadotrofos é influenciada tanto pela secreção de esteróides sexuais, como também sofre modulação dos peptídeos ovarianos, inibina, ativina (ativa a liberação de $\mathrm{FSH}$ ) e folistatina (inibe a secreção de $\mathrm{FSH}$ e se liga à ativina neutralizando a sua função biológica) (HAFEZ, 2004).

Segundo Antoniolli (2002), o FSH age também no início da formação do antro e fluido folicular, na multiplicação das células da teca e granulosa, na formação de receptores para LH e no estímulo da esteroidogênese, que em conjunto com níveis tônicos de LH, atua no sentido de induzir a secreção de estrógeno do folículo ovariano desenvolvido (HAFEZ, 2004). Mas segundo Garverick et al. (2002), o FSH pode sozinho induzir o crescimento folicular até o tamanho de folículo pré-ovulatório, desde que a concentração de FSH permaneça alta o suficiente para que o folículo não seja dependente de LH. Mas isto pode comprometer a funcionalidade do corpo lúteo (WEEB et al., 2003). 
CAETANO, G.A.O., CAETANO JÚNIOR, M.B. e ZMIESKI, E.C. Efeito da duração do período seco sobre a reprodução de vacas leiteiras durante a lactação subsequente. PUBVET, Londrina, V. 8, N. 15, Ed. 264, Art. 1753, Agosto, 2014.

\subsubsection{Hormônio Luteinizante}

O hormônio luteinizante é uma glicoproteína produzida por gonadotrofos no lobo anterior da hipófise (GONZÁLEZ, 2002; HAFEZ, 2004). Os folículos são considerados dependentes de FSH até que ocorra a dominância, depois ele se torna dependente de LH (FORTUNE et al., 2001). Segundo Antoniolli (2002), o folículo destinado a ser dominante possui mais receptores para $\mathrm{LH}$, estabelecendo uma vantagem competitiva sobre os outros folículos que serão os subordinados.

Com o bloqueio parcial da secreção de FSH unido ao pico de liberação de GnRH e a retroalimentação positiva pelo estrógeno no centro pré-ovulatório do hipotálamo (ANTONIOLLI, 2002), ocorre o pico pré-ovulatório de LH, que é responsável pela ruptura da parede folicular do folículo que atingiu a dominância, e consequentemente a ovulação. O LH também é responsável pela luteinização das células remanescente do folículo que ovulou, formando assim, o corpo lúteo, que irá produzir progesterona (HAFEZ, 2004).

O LH também tem a função de induzir a transformação de colesterol em testosterona nas células da teca. Essa testosterona sobre o efeito do FSH nas células da granulosa e se transformará em estrógeno (ANTONIOLLI, 2002).

\subsubsection{Hormônios Esteróides Gonodais}

Os hormônios esteróides são produzidos pelos ovários, mas podem ser produzidos também em certa quantidade pela placenta e adrenais. A hipófise anterior faz o controle endócrino sobre a atividade secretora das gônadas. Os hormônios esteróides podem ser andrógenos, estrógenos e progestágenos. A meia vida dos esteróides naturais do organismo animal é muito curta (HAFEZ, 2004). 
CAETANO, G.A.O., CAETANO JÚNIOR, M.B. e ZMIESKI, E.C. Efeito da duração do período seco sobre a reprodução de vacas leiteiras durante a lactação subsequente. PUBVET, Londrina, V. 8, N. 15, Ed. 264, Art. 1753, Agosto, 2014.

\subsubsection{Estrógenos}

Estrógenos são esteróides produzidos pelas células da teca interna do folículo ovariano. Eles são produzidos a partir de precursores androgênicos e são carregados por proteínas ligadoras pela circulação. De todos os esteróides, os estrógenos são os que mais agregam funções, tendo importância no desenvolvimento das características sexuais secundárias femininas (GONZÁLEZ, 2002).

O folículo de Graff secreta particularmente o estradiol, que é um estrógeno primário, biologicamente ativo. O estradiol, quando em concentrações crescentes, tem a função de induzir o comportamento do cio nas fêmeas, desde que tenha pequenas quantidades de progesterona. Com as concentrações de progesterona diminuindo, o estradiol faz retroalimentação positiva no hipotálamo, fazendo com que aconteça o pico pré-ovulatório de $\mathrm{LH}$, provocando a ovulação (HAFEZ, 2004).

Os estrógenos também têm efeito estimulatório no desenvolvimento das glândulas e ductos mamários, atuam no útero, potencializando os efeitos da ocitocina e de PGF 2a, e ainda possuem efeito anabólico protéico, aumentado o ganho de peso e crescimento (HAFEZ, 2004).

\subsubsection{Progesterona}

A progesterona é um esteróide, secretado pelas células luteínicas do corpo lúteo, pela placenta e glândulas adrenais. Ela é transportada por uma proteína de ligação (GONZÁLEZ, 2002).

Com o pico de LH e a ovulação, a parede do folículo sofre hiperplasia e hipertrofia, ocorrendo um preenchimento da cavidade deixada pelo oócito, formando o corpo lúteo que começa a secretar progesterona (MARTIM, 2003). A progesterona age no útero, aumentando a secreção das glândulas do endométrio e inibindo a motilidade do miométrio, preparando assim, o 
CAETANO, G.A.O., CAETANO JÚNIOR, M.B. e ZMIESKI, E.C. Efeito da duração do período seco sobre a reprodução de vacas leiteiras durante a lactação subsequente. PUBVET, Londrina, V. 8, N. 15, Ed. 264, Art. 1753, Agosto, 2014.

ambiente uterino para a eventual implantação e a conseqüente manutenção da prenhez (HAFEZ, 2004). Na glândula mamária, ela auxilia no desenvolvimento dos alvéolos.

Caso não haja prenhez, o corpo lúteo regride e os níveis de progesterona diminuem chegando a valores ideais (BORGES et al., 2003), que em sinergismo com o estrógeno, induzem o comportamento do cio. Em fase lútea ou em casos de gestação, a progesterona inibe o cio e o pico pré-ovulatório de LH, impedindo a ovulação.

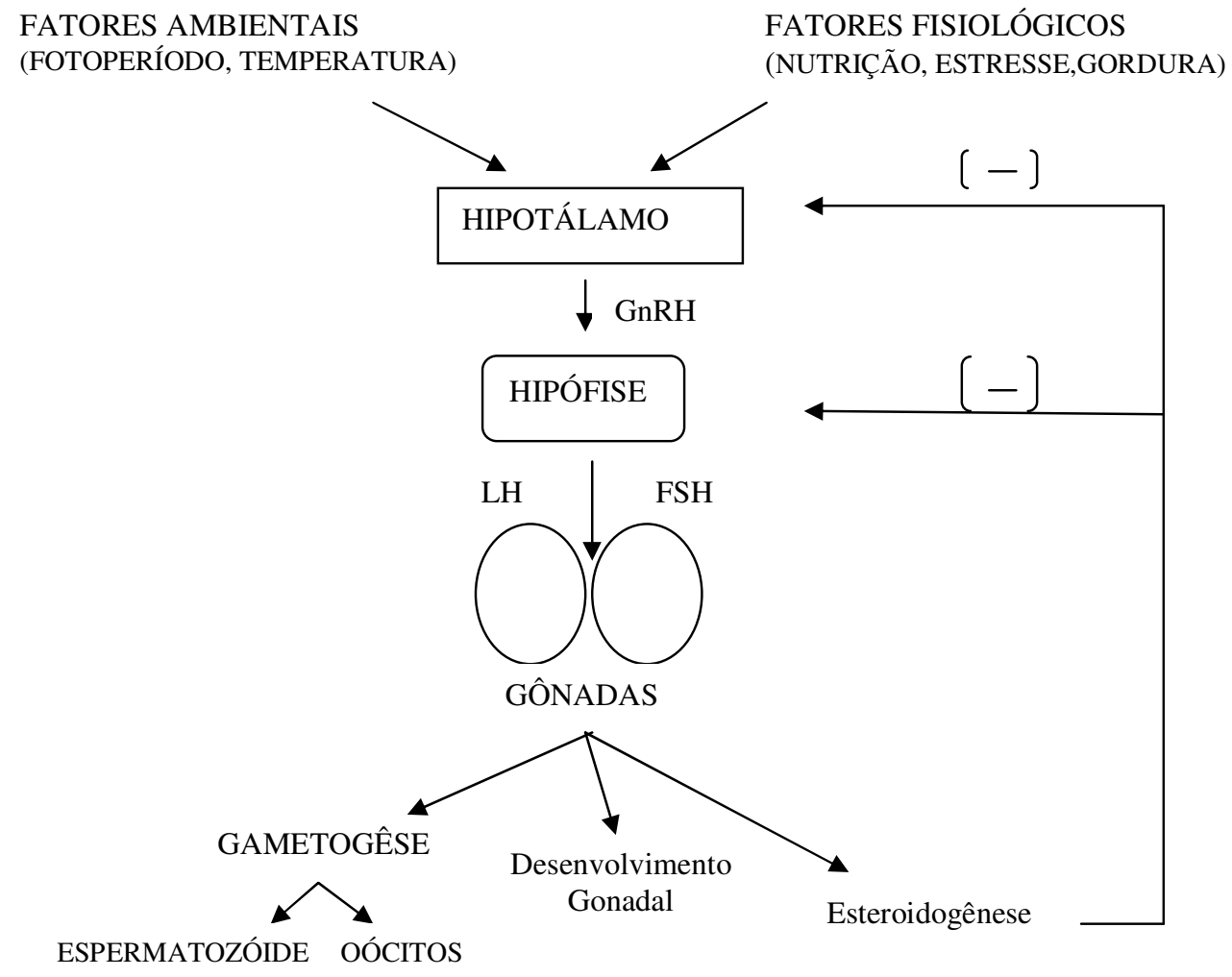

Figura 1: Resumo do Eixo Hipotalâmico Hipofisário Gonadal Fonte: ZULU, NAKAO \& SAWAMUKAI, 2002. 
CAETANO, G.A.O., CAETANO JÚNIOR, M.B. e ZMIESKI, E.C. Efeito da duração do período seco sobre a reprodução de vacas leiteiras durante a lactação subsequente. PUBVET, Londrina, V. 8, N. 15, Ed. 264, Art. 1753, Agosto, 2014.

\section{BALANÇO ENERGÉTICO NEGATIVO}

Levando em conta a correlação genética entre rendimento leiteiro e ingestão de matéria seca, foi calculado que a ingestão de energia de uma vaca de alta produção durante o período que compreende o começo da lactação é menor que a metade da energia necessária para produção. Está bem claro, que vacas em começo de lactação, não conseguem consumir nutrientes energéticos suficientes para abastecer as necessidades de produção e manutenção. Isto caracteriza o balanço energético negativo (BEN), ou seja, é a diferença no consumo da energia liquida consumida menos a energia líquida necessária para produção e manutenção BE = ELi (ingerida) - ELm (necessária para mantença) (JORRITSMA et al., 2003).

Vários estudos apontam associações entre o atraso na primeira ovulação após o parto e redução nas taxas de prenhez com o balanço energético negativo, mobilização de gordura corporal, elevados níveis plasmáticos de ácidos graxos não esterificados (AGNE), e reduzida concentração de insulina (GARNSWORTHY, 2007).

\subsection{Condição de Escore Corporal}

Nos últimos anos, o escore de condição corporal (ECC) tem se tornado um método subjetivo para determinar as reservas energéticas da vaca, sendo baseado na observação visual e palpação de lugares específicos para avaliar reservas de gordura e massa muscular, principalmente no membro posterior e flanco. Como é um método subjetivo, ele deve ser feito sempre por uma mesma pessoa responsável por esta atividade (LAGO et al., 2001).

Existem vários métodos para a classificação, sendo o valor mais alto para vacas mais gordas e valores mais baixos para vacas magras. Edmonson et al. (1989), citado por Lago et al., (2001), propôs uma escala de 1 a 5 com um intervalo de 0,25 pontos para avaliar o ECC. 
CAETANO, G.A.O., CAETANO JÚNIOR, M.B. e ZMIESKI, E.C. Efeito da duração do período seco sobre a reprodução de vacas leiteiras durante a lactação subsequente. PUBVET, Londrina, V. 8, N. 15, Ed. 264, Art. 1753, Agosto, 2014.

O ECC tem uma herdabilidade de cerca de 0,2 a 0,3. Como a correlação entre ECC e fertilidade é amplamente elevada, o ECC pode ser útil em um índice de seleção para melhorar a fertilidade, ou pelo seu uso como um critério de seleção indireta para fertilidade (COSTA, 2007). Em uma análise feita por Lopez-Gatius et al. (2003), com o intuito de avaliar a relação entre o ECC e a eficiência reprodutiva, constatou-se seguintes observações: quando comparado com vacas que perderam 0 a 0,5 unidade do ECC, vacas que perderam 0,5 a 1,0 unidade do ECC levaram 3,5 mais dias para conceber, vacas que perderam mais que 1,0 unidade do ECC levaram 10,6 dias a mais para conceber e vacas que ganharam ECC levaram 3,7 menos dias para conceber.

A avaliação do ECC é indicada para ser feita no momento em que se vai secar a vaca, ao parto, no pico de lactação e no momento da cobertura. Segundo Ferguson (1994), os valores ideais desde a secagem ao parto são de 3,0 a 3,5 .

TABELA 1

Valores para ECC de novilhas e vacas nos seus estádios de produção

\begin{tabular}{|l|l|l|}
\hline \multicolumn{1}{|c|}{ Estádio da lactação } & \multicolumn{1}{|c|}{ ECC ideal } & \multicolumn{1}{c|}{$\begin{array}{c}\text { Intervalo } \\
\text { Sugerido }\end{array}$} \\
\hline Período Seco & 3,50 & $3,25-3,75$ \\
\hline Parto & 3,50 & $3,25-3,75$ \\
\hline Início da Lactação & 3,00 & $2,50-3,25$ \\
\hline Meio da Lactação & 3,25 & $2,75-3,25$ \\
\hline Fim da Lactação & 3,50 & $3,00-3,50$ \\
\hline Novilhas em crescimento & 3,00 & $2,75-3,25$ \\
\hline Novilhas ao parto & 3,50 & $3,25-3,75$ \\
\hline
\end{tabular}

Fonte: FERGUSON, 1994 
CAETANO, G.A.O., CAETANO JÚNIOR, M.B. e ZMIESKI, E.C. Efeito da duração do período seco sobre a reprodução de vacas leiteiras durante a lactação subsequente. PUBVET, Londrina, V. 8, N. 15, Ed. 264, Art. 1753, Agosto, 2014.

As vacas apresentam características individuais para o ECC alvo geneticamente programado. Quando o ECC de uma vaca é acima do alvo, o consumo de alimento é reduzido e ela perde condição corporal, caso contrário, se o ECC estiver abaixo do alvo, a ingestão de alimentos aumenta e a vaca ganha condição corporal (GARNSWORTHY, 2007).

Vacas que chegam ao parto sem reservas corporais apropriadas, ou seja, que perderam ECC no final do período seco podem ser mais susceptíveis a transtornos metabólicos, doenças infecciosas, diminuição na produtividade leiteira, e ter queda na eficiência reprodutiva, por outro lado, vacas obesas estariam mais propensas à síndrome da vaca gorda, partos distócitos, podendo levar muitas vezes à morte.

Vacas com condição de escore corporal muito elevado são mais predispostas à cetose, pelo fato de seu consumo alimentar ser menor logo após o parto e terem a necessidade de mobilizarem mais reservas corporais (BUTLER \& SMITH, 1987).

\subsection{Mudanças fisiológicas no período de balanço energético negativo}

O parto e o início da lactação impõem mudanças fisiológicas grandiosas para o mecanismo de homeostasia da vaca, pois durante o BEN, os eventos homeorréicos sustentam 0 aporte metabólico para a lactação e, aparentemente, a glândula mamária tem prioridades metabólicas sobre a função ovariana. A base fundamental dessas mudanças fisiológicas é assegurar o fornecimento adequado de nutrientes para o bezerro, tanto no pré-natal como no pós-parto (GWAZDAUSKAS et al., 1999).

Durante as três últimas semanas de gestação, a demanda de nutrientes exigidas pelo feto chega ao máximo, enquanto que a ingestão de matéria seca pela vaca pode diminuir de 10 a 30\% comparado com a ingestão durante o início do período seco (DRACKLEY et al., 2005). Mas isto não é tão 
CAETANO, G.A.O., CAETANO JÚNIOR, M.B. e ZMIESKI, E.C. Efeito da duração do período seco sobre a reprodução de vacas leiteiras durante a lactação subsequente. PUBVET, Londrina, V. 8, N. 15, Ed. 264, Art. 1753, Agosto, 2014.

preocupante, pois muitas espécies de mamíferos adquirem este comportamento no final da gestação.

Esta queda na ingestão de matéria seca (IMS), com a aproximação do parto, pode ocorrer devido à queda da concentração de progesterona no sangue e o aumento de estrógeno (DRACKLEY et al., 2005). Segundo Fergunson (2005), o declínio na ingestão de matéria seca (IMS) pode estar associado com aumento da infiltração de gordura no fígado de vacas leiteiras.

$\mathrm{Na}$ recente lactação, a necessidade energética para a produção de colostro, de leite e mantença da vaca leiteira excede a quantidade de energia fornecida pela IMS, resultando em balanço energético negativo (JORRITSMA et al., 2002). O início da rápida produção de leite aumenta a demanda de glicose para a síntese de lactose. Como a maior parte do carboidrato dietético é fermentada no rúmem e pouca glicose é digerida pelo trato digestivo, a vaca tem que contar com uma extensiva gliconeogênese hepática, para que o abastecimento sistêmico de glicose seja feito. A produção de propionato também é insuficiente, em decorrência da baixa IMS, para sintetizar a quantidade de glicose necessária (DRACKLEY et al., 2005). Assim, aminoácidos provenientes da dieta ou da quebra do músculo esquelético, como também o glicerol derivado da mobilização da gordura corporal, podem fornecer o restante para a síntese da glicose (REYNOLDS et al., 2003).

O controle da homeostasia, no início da lactação, assegura que os tecidos corporais, primariamente o tecido adiposo, serão mobilizados para fornecer energia para a produção de leite, já que a IMS neste período é deficiente. Essas adaptações serão muito importantes para o início da lactação e incluem secreção aumentada de hormônio do crescimento $(\mathrm{GH})$, diminuição da resposta do músculo esquelético e tecido adiposo à insulina e participação da leptina, que além do seu papel na regulação da ingestão alimentar e disponibilidade de energia, também pode participar da coordenação do metabolismo durante a transição do estado de gestante para lactante (BLOCK, 2001). 
CAETANO, G.A.O., CAETANO JÚNIOR, M.B. e ZMIESKI, E.C. Efeito da duração do período seco sobre a reprodução de vacas leiteiras durante a lactação subsequente. PUBVET, Londrina, V. 8, N. 15, Ed. 264, Art. 1753, Agosto, 2014.

TABELA 2

Algumas associações entre BEN e reprodução

\begin{tabular}{|c|l|l|}
\hline Estado Metabólico & $\begin{array}{l}\text { Consequências } \\
\text { Metabólicas }\end{array}$ & Efeito na Reprodução \\
\hline & - Perda de peso & - Inibição da secreção de GnRH \\
& - Depleção de & pelo hipotálamo \\
estoque de gordura & - Ausência de pulso de LH \\
& - Depleção Muscular & - Baixas concentrações de FSH \\
Balanço Energético & - Hipoinsulinemia & -Inibição da foliculogênese \\
Negativo & - Hipoglicemia & - Baixo estradiol \\
& - Elevado AGNE & - Alta sensibilidade ao "feed back" \\
& - Elevado GH & negativo \\
& - Baixa leptina & - Anovulação \\
& - Supressão do & - Anestro \\
& sistema IGF & \\
\hline
\end{tabular}

Fonte: SCARAMUZZI et al, 2006

Durante a fase inicial da lactação, o GH, o receptor de GH (GHR), IGF-1 e a insulina coordenam, através de processos fisiológicos, uma série de eventos metabólicos (LUCY, 2005).

No fígado, o GH liga-se ao GHR, controlando a secreção de (IGF-1), que por sua vez faz um "feed back" negativo sobre o hipotálamo e hipófise, diminuindo a secreção de GH. Após o parto, o GHR sofre uma queda, juntamente com o IGF-1, que precisa do GHR para poder ser secretado. Com a queda de IGF-1, a quantidade de GH sanguíneo se eleva, promovendo a mobilização de lipídios, elevando assim, a quantidade de ácido graxo não esterificado (AGNE) sanguíneo (LUCY, 2005).

Os ácidos gordurosos são liberados do tecido adiposo e circulam como ácidos gordurosos não esterificados, sendo a principal fonte de energia para a vaca durante este período. Os AGNE têm três possíveis caminhos no fígado: 
CAETANO, G.A.O., CAETANO JÚNIOR, M.B. e ZMIESKI, E.C. Efeito da duração do período seco sobre a reprodução de vacas leiteiras durante a lactação subsequente. PUBVET, Londrina, V. 8, N. 15, Ed. 264, Art. 1753, Agosto, 2014.

eles podem ser completamente oxidados, fornecendo energia para o fígado; podem ser parcialmente oxidados, resultando em corpos cetônicos, que servirão de combustível para outros tecidos; e podem ser convertidos em triacilglicerídeos (TG). Esses ácidos são secretados em forma de lipoproteína de muito baixa densidade (VLDL). Ruminantes têm, na sua natureza, uma baixa capacidade para sintetizar e secretar lipoproteínas de muito baixa densidade para exportar TG do fígado (DRACKLEY et al., 2005).

A concentração de AGNE no sangue reflete o grau de mobilização de TG do tecido adiposo (DRACKLEY et al., 2005). Quando a quantidade de TG excede a capacidade do fígado de secretá-los em lipoproteína de muito baixa densidade, eles se acumulam no fígado, podendo ocasionar fígado gorduroso, mostrando a pobre adaptação à grande demanda energética da recente lactação (JORRITSMA et al., 2002).

O balanço energético negativo e insuficiência de carboidrato no fígado depois do parto, também levam ao aumento de corpos cetônicos, que podem resultar em cetose clínica ou subclínica (DRACKLEY et al., 2005).

Acredita-se que o GH sanguíneo elevado, age de forma direta, aumentando a gliconeogênese hepática, além de agir de forma indireta junto com o AGNE, através de um antagonismo à ação da insulina e criando um estado de resistência à insulina. O nível de insulina sérico baixo e a resistência à insulina diminuem o uso da glicose pelos tecidos não mamários e direciona a glicose para a síntese de leite (LUCY, 2005).

Já a leptina age no sistema nervoso central, mais especificamente no hipotálamo, como um sinal da reserva energética, reduzindo a ingestão voluntária de alimentos. Segundo Lierfes (2003), as concentrações de leptina estão elevadas durante o fim da gestação e declinam rapidamente com o parto e a recente lactação. Neste período a vaca perde aproximadamente $60 \%$ da sua gordura corporal durante o início da lactação, diminuindo assim as reservas de tecido adiposo e consequentemente a síntese de leptina. 
CAETANO, G.A.O., CAETANO JÚNIOR, M.B. e ZMIESKI, E.C. Efeito da duração do período seco sobre a reprodução de vacas leiteiras durante a lactação subsequente. PUBVET, Londrina, V. 8, N. 15, Ed. 264, Art. 1753, Agosto, 2014.

Em seu estudo, Block et al. (2001) mostrou que a leptina está negativamente relacionada com a quantidade de $A G N E$, que reflete a quantidade de gordura mobilizada. Segundo ele, o provável fator responsável pela queda da leptina plasmática e BEN é a depleção de tecido adiposo, que é mostrada através da perda de escore de condição corporal que está associado com o início da lactação.

Mesmo o sistema regulador total sendo muito complexo, estabeleceu-se que a leptina é o mais provável mecanismo de "feed back". Segundo Garnsworthy (2007), a leptina, além dos seus efeitos no consumo alimentar, tem também efeito modulatório na transferência e direcionamento dos nutrientes através da interação com a insulina, glucagon, glicocorticóides, hormônio do crescimento, fator de crescimento semelhante à insulina, citocinas e hormônio da tireóide.

Segundo Lucy (2005), estes mecanismos acima citados são gradativamente desativados cerca de 4 a 8 semanas do início da lactação. 0 aumento da glicemia acontece quando a síntese de glicose excede a demanda, aumentando os níveis de insulina, que por sua vez aumentam os receptores de GH (RGH). Com isso, ocorre um aumento nos níveis de IGF-1, que faz "feed back" negativo para o $\mathrm{GH}$, reduzindo a mobilização de tecido adiposo.

Com todas essas mudanças fisiológicas e metabólicas que ocorrem durante o período de transição, a função reprodutiva fica prejudicada.

\subsection{Efeito do Balanço Energético na Eficiência Reprodutiva}

O estado nutricional é um fator muito importante que influência a reprodução, afetando a idade à puberdade, anestro pós-parto e a taxa de sobrevivência embrionária. $O$ anestro pós-parto pode ser parcialmente explicado pelo fato das vacas estarem em balanço energético negativo, aumentando o intervalo à primeira ovulação. A ingestão dietética age em 
CAETANO, G.A.O., CAETANO JÚNIOR, M.B. e ZMIESKI, E.C. Efeito da duração do período seco sobre a reprodução de vacas leiteiras durante a lactação subsequente. PUBVET, Londrina, V. 8, N. 15, Ed. 264, Art. 1753, Agosto, 2014.

vários níveis do eixo hipotálamo-pituitária-ovários, controlando a atividade reprodutiva (WEBB et al., 2004).

O folículo ovariano é uma parte fundamental do processo reprodutivo. Sendo assim, é importante que sejam revisados alguns aspectos da dinâmica folicular para que se possa descrever o efeito do balanço energético negativo sobre este importante constituinte do mecanismo reprodutivo.

\subsubsection{Fisiologia das Ondas Foliculares}

Segundo Lucy et al., (1991), a dinâmica folicular é o processo contínuo de crescimento e atresia dos folículos pré-ovulatórios; e onda de crescimento folicular é o padrão de crescimento e atresia de um grupo de folículos ovarianos, que iniciam o desenvolvimento sincronicamente em determinados períodos do ciclo estral.

O ovócito é a célula germinativa que se encontra dentro do folículo ovariano, o qual é constituído de granulosa, cujas células são capazes de sintetizar hormônios e reguladores das funções celulares como o estradiol, progesterona, IGF I, inibina, ativina e EGF dentre vários outros, além da teca interna e externa, que possui relação metabólica com as células da granulosa, sendo capaz de produzir substratos para a produção de estradiol (GONZÁLEZ, 2002).

Durante a vida fetal ou logo após o nascimento é formada uma reserva de folículos primordiais (HAFEZ, 2004), os quais são recrutados ao longo da vida da fêmea, para que um possa chegar à ovulação.

O crescimento do folículo pré-antral é depende de fatores intraovarianos, como a presença da interação do oócito com a granulosa, em que o oócito participa na indução da proliferação e diferenciação das células da granulosa e a secreção de uma gama de fatores produzidos localmente (WEBB, 2004). Sendo assim, não há dependência de gonadotrofinas até a formação do 
CAETANO, G.A.O., CAETANO JÚNIOR, M.B. e ZMIESKI, E.C. Efeito da duração do período seco sobre a reprodução de vacas leiteiras durante a lactação subsequente. PUBVET, Londrina, V. 8, N. 15, Ed. 264, Art. 1753, Agosto, 2014.

antro, embora alguns estudos mostram que o $\mathrm{FSH}$ pode acelerar a taxa de desenvolvimento do folículo pré-antral (WEBB et al., 2004).

O padrão de pulso normal de $\mathrm{LH}$ é a chave para o retorno do desenvolvimento folicular ovariano e o início da atividade cíclica da vaca. Mas em vacas leiteiras no início de lactação, o LH parece estar reduzido após 5 a 10 dias pós-parto (DRACKLEY et al., 2005).

O crescimento do folículo antral é dependente das gonadotrofinas, as quais têm o papel de induzir o recrutamento e crescimento de folículos antrais de forma sincronizada em ondas foliculares.

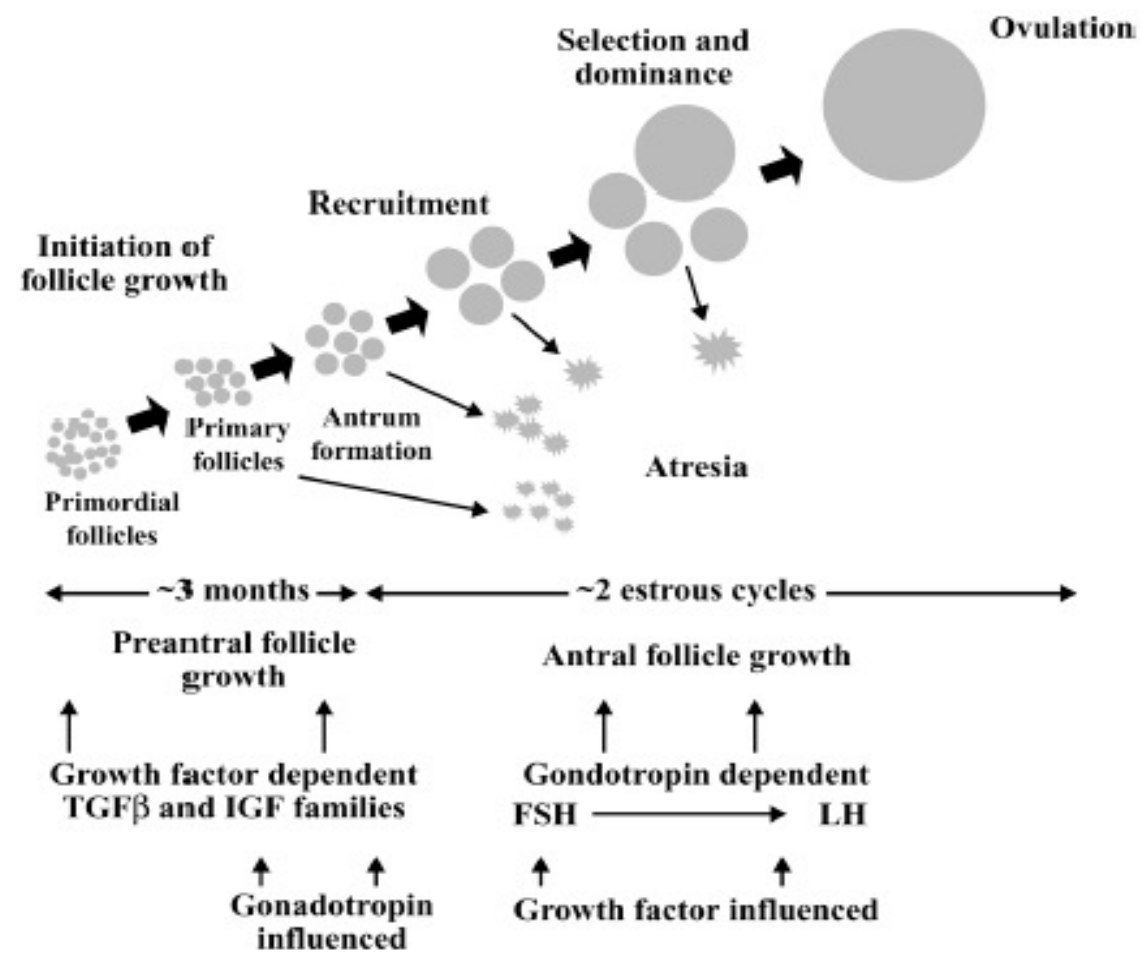

Figura 2: Crescimento folicular contínuo. Folículo pré-antral: não dependente de gonadotrofinas; folículo anteral: dependente de gonadotrofinas.

Fonte: WEBB et al. 2004 
CAETANO, G.A.O., CAETANO JÚNIOR, M.B. e ZMIESKI, E.C. Efeito da duração do período seco sobre a reprodução de vacas leiteiras durante a lactação subsequente. PUBVET, Londrina, V. 8, N. 15, Ed. 264, Art. 1753, Agosto, 2014.

O estágio final do desenvolvimento do folículo antral é caracterizado por duas ou três ondas de crescimento foliculares durante cada ciclo estral. Uma ou quatro ondas já são mais raras de acontecer (BURATINI, 2007). Cada onda folicular tem um período de vida de aproximadamente de 7 a 10 dias com um processo contínuo de vários estágios de desenvolvimento que abrangem a emergência, seleção, dominância, podendo evoluir para atresia ou ovulação (DISKIN et al., 2003).

Cada onda folicular é precedida por um aumento de $\mathrm{FSH}$, que consiste em um estímulo necessário para o recrutamento e emergência da onda. Os folículos recrutados sofrem seleção, onde só um será selecionado para ser o folículo dominante (FD), e os outros folículos sofrem atresia. O mecanismo pelo qual acontece a seleção e dominância ainda não está claramente explicado, mas acredita-se que todos os folículos possam contribuir para o declínio inicial de FSH (WEBB et al. 2004). O FD é distinguível dos folículos subordinados pela sua maior capacidade de produzir estradiol (DISKIN et al., 2003).

Com a secreção de estradiol e inibina, que são produzidos sobretudo pelas células da granulosa do FD, ocorre um "feed back" negativo na hipófise anterior, suprimindo a liberação de FSH a níveis abaixo do limiar necessário para manter o crescimento dos folículos subordinados, que consequentemente se tornará atrésicos (CASTILHO \& GARCIA, 2005). A seleção do FD ocorre durante o declínio das concentrações de FSH, no qual o FD se mantém em concentrações baixas até a ovulação ou atresia deste, dependendo do padrão de secreção do hormônio luteinizante (LH).

Durante o estágio final da seleção, o folículo dominante passa por uma transição de FSH dependente para LH dependente (DISKIN et al., 2003). Segundo Fortune et al., (2004), o crescimento dos folículos antrais entre 4 a $8 \mathrm{~mm}$ diâmetro ocorre na dependência de FSH, já os folículos maiores que 9 $\mathrm{mm}$ mostram-se dependentes de $\mathrm{LH}$, sugerindo que os folículos só são dependentes de FSH até a dominância, tornando-se dependentes de LH após 
CAETANO, G.A.O., CAETANO JÚNIOR, M.B. e ZMIESKI, E.C. Efeito da duração do período seco sobre a reprodução de vacas leiteiras durante a lactação subsequente. PUBVET, Londrina, V. 8, N. 15, Ed. 264, Art. 1753, Agosto, 2014.

este evento. Segundo Diskin et al. (2003), o FD expressa nas células da granulosa o RNAm para receptores de LH (LHR), permitindo que o FD continue o seu crescimento sob estimulo do LH.

O sistema IGF parece exercer um papel crucial na seleção do folículo dominante, pois este faz sinergismo com o $\mathrm{FSH}$, promovendo o crescimento folicular, aumentando assim, a produção de estradiol. Segundo revisão de Webb et al. (2004). O IGF-1, como também a insulina, interage com o FSH para estimular a produção de estradiol pelas células da granulosa.

\subsubsection{Mecanismo pelo qual o BEN afeta a função ovariana}

A nutrição pode exercer influência na função ovariana através de vários mecanismos incluindo efeitos sistêmicos: no hipotálamo através da síntese e liberação de $\mathrm{GnRH}$; na pituitária anterior através do controle da síntese e liberação de $\mathrm{LH}, \mathrm{FSH}, \mathrm{GH}$; e no ovário através da regulação crescimento folicular e síntese de esteróides. Além destes efeitos sistêmicos sobre o ovário, existe a possibilidade da nutrição exercer influência dentro do ovário através da cascata de fatores de crescimento e suas proteínas ligadoras (DISKIN et al., 2003).

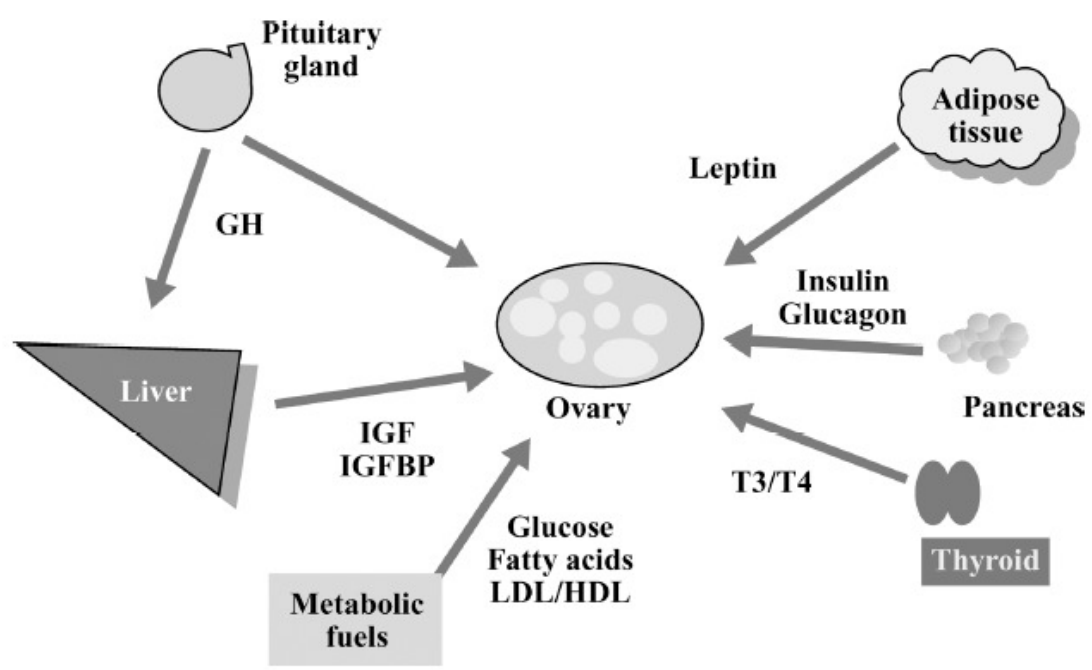

Figura 3: A influência dos fatores metabólicos na função ovariana.

Fonte: WEBB et al., 2004. 
CAETANO, G.A.O., CAETANO JÚNIOR, M.B. e ZMIESKI, E.C. Efeito da duração do período seco sobre a reprodução de vacas leiteiras durante a lactação subsequente. PUBVET, Londrina, V. 8, N. 15, Ed. 264, Art. 1753, Agosto, 2014.

O primeiro efeito da baixa disponibilidade de combustíveis metabólicos, além da ativação de opióides neuroendócrinos, é a inibição do pulso gerador de GnRH. Isto leva a uma cascata de eventos que incluem: inibição da secreção de LH e FSH; inibição do desenvolvimento folicular; inibição da secreção de estrógeno e progesterona. Os efeitos inibitórios destes esteróides levam a inibição da onda de LH (SCHNEIDER, 2004).

Para que o desenvolvimento folicular ovariano e o retorno da atividade cíclica ocorram é necessário que o padrão de pulso de LH se restabeleça. Pelo dia 10 depois do parto a freqüência de pulso de LH aumenta, resultando em estimulação do desenvolvimento folicular (LUCY et al., 1991). Entretanto, a baixa ingestão de matéria seca característica do BEN no início da lactação, acarreta uma queda na concentração de glicose circulante, induzindo a lipólise, resultando em baixa liberação de LH, impedindo assim o desenvolvimento folicular (KENDRICK et al., 1999).

Segundo Block et al. (2001), vacas no início do período pós-parto tiveram menores concentrações de leptina, insulina e glicose, enquanto as concentrações de $\mathrm{GH}$ e ácidos graxos não esterificados estavam aumentados. Estes sinais metabólicos resultam em atraso no aumento dos pulsos de $\mathrm{LH}$ e FSH que são necessários para estimular o desenvolvimento dos folículos ovarianos.

Alguns autores sugerem que a concentração de insulina mais que a concentração de glicose possa afetar diretamente a secreção de LH (BUTLER, 2006). Além disso, a insulina tem um papel na regulação da responsividade dos ovários à gonadotrofina, pois pode ocorrer uma inabilidade de resposta ao aumento da freqüência do pulso de LH devido à falta de receptores de LH nas células da granulosa. Além do mais, quando em baixas concentrações, a insulina pode reduzir a produção de andrógeno e estradiol, comprometendo assim a habilidade dos folículos de adquirir receptores para LH (DISKIN et al., 2003). 
CAETANO, G.A.O., CAETANO JÚNIOR, M.B. e ZMIESKI, E.C. Efeito da duração do período seco sobre a reprodução de vacas leiteiras durante a lactação subsequente. PUBVET, Londrina, V. 8, N. 15, Ed. 264, Art. 1753, Agosto, 2014.

Durante o BEN, as concentrações de GH se encontram aumentadas, mas o fígado neste período é refratário, ou seja, "resistente ao $\mathrm{GH}^{\prime}$. A queda das concentrações de insulina, que é uma resposta inicial para o BEN do início da lactação, pode ser responsável pela queda de receptores de hormônio do crescimento (GHR) no fígado, sendo que a concentração destes tem uma correlação positiva com o IGF-1 plasmático (BUTLER et al., 2003). Sendo assim, a circulação de IGF-1 plasmático se encontra em baixas concentrações, acentuada pela reduzida secreção de LH devido ao BEN. Como é sabido o IGF1 é muito importante no processo reprodutivo, e baixas concentrações de IGF1 sérico podem contribuir para a não ovulação, desenvolvimento de cistos e supressão do comportamento do estro.

Isto acontece devido ao prejuízo causado à proliferação das células da granulosa e da teca, levando à baixa produção de estradiol, consequentemente à falta de onda pré-ovulatória de $\mathrm{LH}$ e à falta de receptores de $\mathrm{LH}$ nas células da granulosa de folículos pré-ovulatórios (ZULU, NAKAO \& SAWAMUKAI, 2002).

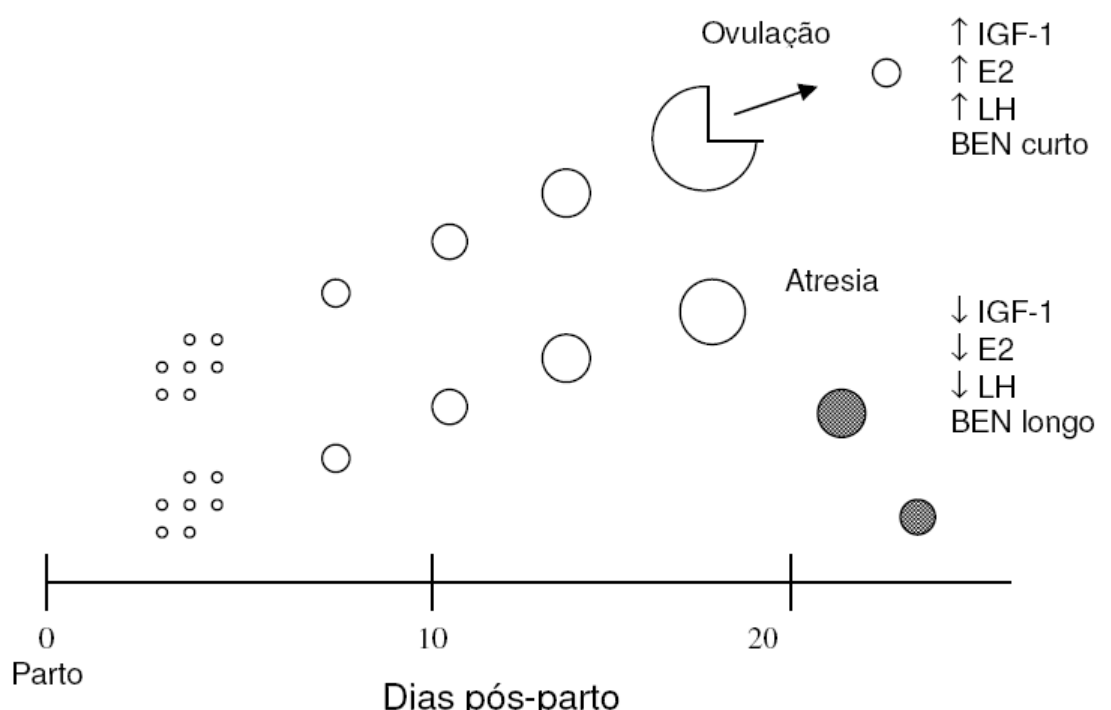

Figura 5: Modelo Esquemático descrevendo os eventos reprodutivos e metabólicos pós-parto em vacas leiteiras.

Fonte: ZULU, NAKAO \& SAWAMUKAI, 2002. 
CAETANO, G.A.O., CAETANO JÚNIOR, M.B. e ZMIESKI, E.C. Efeito da duração do período seco sobre a reprodução de vacas leiteiras durante a lactação subsequente. PUBVET, Londrina, V. 8, N. 15, Ed. 264, Art. 1753, Agosto, 2014.

Segundo Lucy et al. (2001), a dinâmica folicular de vacas em BEN é caracterizada por ondas de crescimento folicular e atresia sem ovulação, o que resulta em atraso a primeira ovulação, consequentemente aumenta o intervalo entre partos.

\subsubsection{A influência do BEN nos folículos e oócitos}

A nutrição pode induzir mudanças tanto na dinâmica folicular como na qualidade do oócito, pois as concentrações de hormônios metabólicos e fatores de crescimento, que exerce influência sobre estes parâmetros, se encontram alterados no período de balanço energético negativo (WEBB et al., 2004). Segundo Lucy et al. (1991), a redução nas concentrações plasmáticas de IGF1 é acompanhada por uma diminuição do crescimento folicular.

Lucy et al. (1991), realizaram um estudo em que 52 vacas no período de pós parto foram analisadas com o propósito de avaliar o retorno do crescimento folicular com o auxilio da ultra-sonografia, e também para determinar como o balanço energético influencia nas mudanças na população folicular ovariana. Eles encontraram resultados que indicaram que o balanço energético parece afetar e mudar o número médio de folículos nos primeiros 25 dias do pós-parto. Neste período, o número de folículos de classe 1 ( 3 a 5 $\mathrm{mm}$ ) e classe 2 (6 a 9mm), diminuíram com o passar dos dias pós-parto. Já os folículos de classe 3 (10 a $15 \mathrm{~mm}$ ) e classe 4 (>15mm) aumentaram. Sendo estes dados consistentes com o conceito de recrutamento folicular e seleção, levando ao crescimento terminal e dominância.

Estas descobertas sugerem que o balanço energético negativo exerce efeitos sobre o crescimento folicular no início de lactação, consequentemente influencia o intervalo à primeira ovulação por influenciar a evolução dos folículos em direção a classes de folículos de maior tamanho. 
CAETANO, G.A.O., CAETANO JÚNIOR, M.B. e ZMIESKI, E.C. Efeito da duração do período seco sobre a reprodução de vacas leiteiras durante a lactação subsequente. PUBVET, Londrina, V. 8, N. 15, Ed. 264, Art. 1753, Agosto, 2014.

Segundo Chagas et al. (2007) a qualidade do oócito é afetada por uma interação entre nível alimentar e condição corporal, pois animais de baixa condição corporal, que receberam um alto nível alimentar, tiveram seus oócitos beneficiados. Já animais com moderada ou alta condição corporal, tiveram oócitos prejudicados. Isto indica que os fatores metabólicos relacionados com a nutrição, ou seja, com o período de BEN, podem influenciar os oócitos de folículos pré-antral.

Kendrick et al. (1998), realizaram um trabalho onde as vacas foram divididas em dois diferentes grupos. Um grupo recebia dieta de alta energia e o outro uma dieta de baixa energia. Os oócitos foram aspirados e analisados. As vacas que receberam alimentação altamente energética tiveram maiores concentrações de IGF-1 e produziram maior número de oócitos de boa qualidade, quando comparado às vacas que receberam alimentação de baixa energia. Independente do tratamento fornecido para as vacas, a qualidade e o número dos oócitos foram melhores após 30 dias pós-parto. Neste mesmo trabalho, Kendrick et al. (1998), analisou as concentrações de progesterona em ambos os grupos, revelando que as concentrações séricas de progesterona durante o diestro do primeiro e segundo ciclo estral foram maiores em vacas que se apresentavam em balanço energético positivo, sugerindo que a função luteal é adversamente afetada pelo BEN.

\section{PERÍODO SECO}

O período seco (PS) da vaca sempre foi definido como os dois últimos meses de gestação, importante para se adotar práticas especiais, a fim de proporcionar boas condições de parição e proteger a saúde da futura cria. No período em que está seca, a vaca tem que realizar grandes tarefas, como o desenvolvimento de $2 / 3$ do feto e a recuperação de reservas corporais para o próximo parto e a nova lactação. 
CAETANO, G.A.O., CAETANO JÚNIOR, M.B. e ZMIESKI, E.C. Efeito da duração do período seco sobre a reprodução de vacas leiteiras durante a lactação subsequente. PUBVET, Londrina, V. 8, N. 15, Ed. 264, Art. 1753, Agosto, 2014.

Segundo ALMEIDA (2009), o PS é considerado parte importante do ciclo completo de manejo do gado leiteiro. Os pecuaristas de leite de maior êxito sabem que o PS não significa o fim de um ciclo de lactação, mas o início da próxima. Os fatores de risco para a maioria das doenças pós-parição em vacas leiteiras são observados durante o PS, sendo que os sinais clínicos das doenças ficam evidentes após a parição.

Um período seco de 60 dias vem, há muito tempo, sendo adotado pela maioria dos criadores de gado leiteiro a fim de permitir, entre uma lactação e outra, a regeneração dos tecidos epiteliais desgastados da glândula mamária, acumular colostro e assegurar o desenvolvimento do feto, e por último completar as reservas corporais, quando estas ainda não ocorreram. LINO (2009) disse que os motivos que levam à adoção de um PS reduzido, são:

incremento na produção de leite, na lactação em questão, pelo aumento do número de dias em que a vaca é ordenhada; simplificação do manejo de vacas secas; diminuição de desordens metabólicas; alívio na superlotação das instalações para vacas secas.

Todavia, segundo FERREIRA et al. (2007) a falta de cuidados adequados na seca ocasiona queda na produção de leite na lactação seguinte, redução na vida reprodutiva da vaca, alongamento do intervalo de partos, nascimento de bezerros fracos e aumento de problemas sanitários. A vaca deve ser bem manejada durante todo o período de lactação, para que no momento de secagem apresente boas condições de saúde e boa condição nutricional.

\subsection{Duração do período seco}

Numerosos fatores influenciam a produção de leite durante a vida de vacas leiteiras. Idade ao primeiro parto, dias abertos, período seco, e a vida do rebanho, são parâmetros importantes a quantidade de leite produzido na vida de uma vaca. A vida produtiva varia consideravelmente entre vacas e é geralmente determinada pela produção de leite, a saúde ou status reprodutivo 
CAETANO, G.A.O., CAETANO JÚNIOR, M.B. e ZMIESKI, E.C. Efeito da duração do período seco sobre a reprodução de vacas leiteiras durante a lactação subsequente. PUBVET, Londrina, V. 8, N. 15, Ed. 264, Art. 1753, Agosto, 2014.

da vaca. Por outro lado, a idade ao primeiro parto, dias abertos, e os dias secos são decisões de gestão que tendem a ser fixado para um determinado rebanho e são bastante consistentes em rebanhos. Recomendações para estes parâmetros são normalmente baseados em extensa pesquisa e são pensados para ser aplicável à maioria dos rebanhos. No entanto, a importância destas recomendações, determinam o que ocasionalmente deve ser reavaliado como os avanços na genética, tecnologias e práticas de gestão lugar.

O PS ideal tem sido debatido por muito tempo. Arnold et al (1936), indicou que havia uma diferença entre os agricultores Ingleses, alguns favorecendo um PS de dois meses, enquanto outros acreditavam que períodos curtos de dez dias suficientes. Reduzir o período seco a partir de 60 dias tem sido considerado benéfico se a produção de leite adicional de estender os deslocamentos lactação ou excede qualquer perda na produção de leite da lactação seguinte. Os componentes do leite também devem ser considerados quando da determinação da viabilidade econômica da redução do PS, especialmente para os países em um sistema de cotas (Remond et al., 1997).

Efeitos do comprimento de PS ou de ordenha contínua na qualidade do colostro, metabólicas e infecciosas, e desempenho reprodutivo de vacas também devem ser considerados ao selecionar um comprimento de PS ideal. $O$ impacto do comprimento do PS em outros aspectos da gestão também pode ter ramificações econômicas. Por exemplo, a eliminação de um longo PS pode aliviar a superlotação das instalações de vaca seca ou eliminar a necessidade para instalações de vacas secas em locais remotos.

A maioria dos estudos que levaram à recomendação de um 60 dias de PS foram concluídas antes de 1990 . Hoje, as tecnologias, tais como bST e práticas de gestão, aumento da freqüência de ordenha são comuns. Talvez o comprimento PS ideal seja diferente para as vacas, nestas condições, comparadas com as de gestão implementadas antes de 1990. A IATF permite uma maior precisão na predição de datas do parto, o que diminui a necessidade de aumentar os dias de seca para dar conta dos inesperados 
CAETANO, G.A.O., CAETANO JÚNIOR, M.B. e ZMIESKI, E.C. Efeito da duração do período seco sobre a reprodução de vacas leiteiras durante a lactação subsequente. PUBVET, Londrina, V. 8, N. 15, Ed. 264, Art. 1753, Agosto, 2014.

partos precoce. Além disso, o aumento do conhecimento da biologia mamária pode resultar em novas estratégias para reduzir a duração do PS.

\subsection{Efeitos do comprimento período seco na produção de leite}

Há uma extensa lista de relatórios que indicam redução do PS abaixo 5060 dias resulta em uma redução na produção de leite da lactação seguinte. Muitos desses estudos foi uma análise retrospectiva dos registos de exploração (Sanders, 1928; Arnold et al., 1936; Dickerson \& Chapman, 1939; Gill \& Allaire, 1976; Pandy et al., 1978; Dias \& Allaire, 1982; Keown \& Evert, 1986; Funk et al., 1987; Makzuka \& McDaniel, 1996). Utilização dos dados destes estudos vem sendo criticados porque as vacas com PS curto normalmente pariram cedo (por exemplo, vacas com gêmeos, as vacas que espontaneamente abortados, vacas com datas de criação incorretas). Por conseguinte, estas vacas não eram geridas por um curto PS. Além disso, as vacas não foram distribuídas aleatoriamente para tratamento e, portanto, vícios são susceptíveis.

Uma alternativa para análise retrospectiva dos registos de exploração, para avaliar os efeitos do comprimento PS são projetados nos experimentos (Bachman, 2002; Gulay et al.,2003; Rastani et al., 2003), ou seja, os pesquisadores atribuem aleatoriamente vacas ou quartos, dentro de tratamentos de comprimento PS diferente. O risco de parcialidade e má interpretação dos resultados é reduzido, no entanto, esses estudos geralmente utilizam o número de vacas limitado, e as chances de cometer um erro tipo II pode ser elevada quando declara que a redução do PS não causou diferença significativa na produção de leite.

Os dois primeiros estudos (Swanson, 1965; Smith et al., 1967), que empregava os tratamentos projetados para examinar os efeitos da eliminação do PS utilizando modelos para reduzir a variação: gêmeos idênticos e tratamento de quartos dentro de uma glândula mamária (metade do úbere ). 
CAETANO, G.A.O., CAETANO JÚNIOR, M.B. e ZMIESKI, E.C. Efeito da duração do período seco sobre a reprodução de vacas leiteiras durante a lactação subsequente. PUBVET, Londrina, V. 8, N. 15, Ed. 264, Art. 1753, Agosto, 2014.

Ambos os estudos indicam perdas significativas na produção de glândulas que foram continuamente ordenhadas. A validade do modelo de meio úbere tem sido questionada (Fowler et al., 1991). O pressuposto é que qualquer diferença na produção de leite na lactação subsequente entre as glândulas é devido à diminuição da produção de leite pelas glândulas que eram continuamente ordenhadas. Possivelmente a diferença ocorre, no todo ou em parte, à maior produção de leite pelas glândulas que não foram continuamente ordenhadas.

Quando uma glândula deixa de ser ordenhadas, o crescimento mamário e produção de leite das outras glândulas podem aumentar de forma compensatória, e isso pode aumentar a produção de leite de uma glândula durante a lactação subsequente. Além disso, é possível que a ordenha contínua possa induzir a lactação nos quartos não ordenhados antes do parto e a falta de retirada do leite pode ter efeitos negativos sobre a lactação subsequente. Infelizmente, o modelo do meio úbere não permite determinar se a produção total de leite pela glândula foi reduzida.

Muitas vezes falta nos relatórios de estudos destinados, em particular os estudos mais antigos, é uma descrição da gestão das vacas durante o período de tratamento. Por exemplo, informações sobre dietas e instalações é frequentemente omitido. Quando essa informação é fornecida, rapidamente se percebe que a duração do PS se confunde com a alimentação, instalação, ou ambos.

Independentemente do modelo (gêmeos idênticos, metade do úbere, a atribuição aleatória de vacas em tratamento), todos os estudos que analisam os efeitos da ordenha contínuo e sem PS em vacas tratadas com bST não indicam que o PS é essencial para evitar reduções significativas na produção de leite a lactação seguinte (Rastani et al., 2003). A redução na produção de leite foi bastante consistentes entre os estudos, cerca de $20-25 \%$. 
CAETANO, G.A.O., CAETANO JÚNIOR, M.B. e ZMIESKI, E.C. Efeito da duração do período seco sobre a reprodução de vacas leiteiras durante a lactação subsequente. PUBVET, Londrina, V. 8, N. 15, Ed. 264, Art. 1753, Agosto, 2014.

\subsection{Efeitos do comprimento período seco sobre a reprodução}

Dados sobre os efeitos de comprimento do PS e os subsequentes efeitos reprodutivos são escassos. Estudos anteriores relataram semelhantes números de inseminações e taxas de prenhez em vacas com PS de 30 e 60 dias, com a produção de leite similar. No entanto, havia apenas nove animais por tratamento. Gumen et al. (2003) relataram o momento do parto até a ovulação pós-parto primeiro foi de 14,5, 21,5 e 28,9 dias para vacas com 0 , 28 ou 56 dias de PS. As diferenças entre os tratamentos neste experimento pode ter sido relacionada ao balanço energético pós-parto e a perda foi inversamente relacionada com a duração do PS (Rastani et al. 2003). O tempo para primeira ovulação pós-parto tem sido relacionado ao $\mathrm{BE}$ e tempo para $\mathrm{BE}$ positivo ( Lucy et al., 1991). A retomada do ciclo estral é importante, porque há evidências de que o número de partos por uma vaca que ovula antes de 60 dias pós-parto é maior.

\section{CONSIDERAÇÕES FINAIS}

Os dados disponíveis indicam que 30 dias de período de seca em vacas pode ser viável, e que resultados de período de seca interruptos culminam em perdas significativas na produtividade de leite durante a lactação subsequente (perda de 20-25\%). Porém, na Universidade do Arizona, uma pesquisa indica que a perda de leite associado com zero dias secos podem ser evitados em multíparas, ao tratamento contínuo com bST.

Nem a prostaglandina 2 a ou o manejo de quatro ordenhas após o parto podem impedir a perda de rendimento associados com ordenha contínua de vacas primíparas. Os resultados preliminares da Universidade de Wisconsin indicam que ordenha 4 vezes / dia, durante o final de 4 semanas de prenhez, pode eliminar a perda de produção associada a um período de 0 dias secos em 
CAETANO, G.A.O., CAETANO JÚNIOR, M.B. e ZMIESKI, E.C. Efeito da duração do período seco sobre a reprodução de vacas leiteiras durante a lactação subsequente. PUBVET, Londrina, V. 8, N. 15, Ed. 264, Art. 1753, Agosto, 2014.

bovinos adultos. Mais pesquisas básicas são necessárias para investigar os fatores que afetam a persistência da lactação, incluindo a proliferação e morte das células mamárias, de modo que as estratégias futuras podem ser desenvolvidas para reduzir ou eliminar o período seco.

\section{REFERÊNCIAS BIBLIOGRÁFICAS}

ANTONIOLLI, Claudia Briani. Desenvolvimento folicular, ondas foliculares e manipulação. In: SEMINÁRIO DE ENDOCRINOLOGIA DA REPRODUÇÃO, 169, Rio Grande do Sul. Anais... Rio Grande do Sul: Pós Graduação em Ciências Veterinárias da UFRGS, 2002, p. 115.

BINELLI, M.; IBIAPINA B.T.; BISINOTTO, R.S. Bases fisiológicas, farmacológicas e endócrinas dos tratamentos de sincronização do crescimento folicular e da ovulação. Acta Scientiae Veterinaria, v. 34, p. 1-7, 2006

BLOCK, S.S.; BUTLER, W.R; EHRHARDT, R.A.; BELL, A.W. Decreased concentration of plasma leptin in periparturient dairy cows is caused by negative energy balance. Journal of Endocrinology, v. 171, p. 339-348, 2001.

BORGES, A.M; TORRES, C.A.A; RUAS, J.R.M; ROCHA, V.R.J; CARVALHO, G.R. Desenvolvimento luteal e concentrações plasmáticas de progesterona em vacas das raças Gir e Nelore. Revista Brasileira de Zootecnia, v. 32, n. 02, p. 276-283, 2003.

BURATINI, JR., Controle endócrino e local da foliculogênese em bovinos. Revista Brasileira de Reprodução Animal, v. 31, n. 2, p. 190-196, 2007.

BUTLER, W.R.; SMITH, R.D. Interrelationships betwen energy balance and pospartum reproductive function in dairy cattle. Journal Dairy Science, v.72, p. 767- 783, 1987.

BUTLER, W.R. Relationship of negative energy balance with fertility. Pen State Dairy Cattle Nutrition Workshop, of octuber 31 and November 1, p. 51-60, 2006.

CANFIELD, R.W. \& BUTLER W.R. Energy balance and pulsatile luteinizing hormone secretion in early postpartum dairy cows. Domestic Animal Endocrinology, v. 7, 323-330p., 1990.

CANFIELD, R. W., SNIFFEN, C. J. AND BUTLER, W. R.. 1990. Effects of excess degradable protein on postpartum reproduction and energy balance in dairy cattle. J. Dairy Sci. 73:23422349.

CASTILHO, C.; GARCIA, J.M. Divergência no crescimento folicular: efeito na competência oocitária para reprodução in vitro de embriões - Revisão. Archieves of Veterinary Science, v. 10, n. 3, p. 17-23, 2005.

CHAGAS, L. M; BASS, J. J; BLACHE, D; BURKE, C. R; KAY, J. K; LINDSAY, D. R; LUCY, M. C; MARTIN, G. B; MEIER,S; RHODES, F. M; ROCHE, J. R; THATCHER; W. W; WEBB, R. Invited Review: New Perspectives on the Roles of Nutrition and Metabolic Priorities in the Subfertility of High-Producing Dairy Cows. Journal Dairy Science, v. 90, p. 4022-4032, 2007. 
COSTA, D.L.C. Escore da condição corporal (ECC) é muito importante para o gado leiteiro. Uberlândia, 2007. Disponível em: http://www.cotrisoja.com.br/artigos/art-2007-0503.html>. Acesso em 24 abril 2013.

DARWASH, A. O., LAMMING, G. E. AND WOOLLIAMS, J. A.. 1997. The phenotypic association between the interval to post-partum ovulation and traditional measures of fertility in dairy cattle. Animal Science 65:9-16.

DISKIN, M.G., MACKEY, D.R, ROCHE J.F, SREENAM J.M. Effects of nutrition and metabolic status on circuling hormones and ovarian follicle development in cattle. Animal Reproduction Science, v. 78, p. 345-370, 2003.

DRACKLEY, J.K; DANN, H.M; DOUGLAS, G.N.; GURETZKY, N.A.F.; LITHERLAND, N.B.; UNDERWOOD, J.P., LOOR, J.J. Physiological and pathological adaptations in dairy cows that may increase susceptibility to periparturient diseases and disorders. Italian Journal of Animal Science, v. 4, p. 323-344, 2005.

FORTUNE, J.E.; RIVERA, G.M.; YANG, M.Y.; Follicular development: the role of the follicular microenvironment in selection of the follicle. Animal Reproduction Science, v. 82-83, p. 109-126, 2001.

GARNSWORTHY, P. Manipulação do Balanço energético negative e implicações na fertilidade. In: CURSO NOVOS ENFOQUES NA PRODUÇÃO E REPRODUÇÃO DE BOVINOS, 3, 2007, Uberlândia. Anais...Uberlândia: 2007. p. 12-21.

GARVERICK, H.A.; BAXTER, G.; GONG, J.;ARMSTRONG, D.G.;CAMPBELL, B.K.; GUTIERREZ C.G.; WEBB R. Regulation of expression of ovarian mRNA encoding hypogonadotrophic catle. Reproduction, v. 123, p. 651-661, 2002

GIBBONS, J.R.; WILTBANK, M.C, GINTHER, O.J. Functional interrelationships between follicles greater than $4 \mathrm{~mm}$ and the follicle-stimulating hormone surge in heifers. Biology Reproduction,v. 57, p. 1066-.1073, 1997.

GONG, J.G; CAMPBEL, B.K; BRAMLEY T.A.; GUTIERREZ, C. G.; PETERS A.R.; WEBB, R.; Supression in the secretion of follicle-stimulating hormone and luteininzing hormone, and ovarian follicle development in heifers continuously infused with a gonadotropin-releasing hormone agoinst. Biology Reproduction, v. 55, p. 68- 74, 1996.

GONZÁLEZ, F.H.D. Introdução à endocrinologia reprodutiva veterinária. Porto Alegre. 2002. 87f. Tese (livre docência) Universidade Federal do Rio Grande do Sul.

Disponível em: <http://www.ufrgs.br/favet/bioquimica/posgrad/. Acesso em: 01 de abril de 2013.

GUMEN, A., RASTANI RR, GRUMMER RR, E WILTBANK MC. 2003. Efeitos de diferentes duração do período seco e dieta prepartum sobre a reprodução em gado leiteiro. Journal Dairy Science. 86 (Suppl. 1): 239 (Abstr.).

GUMEN, A., R. R. RASTANI, R. R. Grummer, and M. C. Wiltbank. (2005) Reduced dry periods and varying prepartum diets alter postpartum ovulation and reproductive measures. Journal Dairy Science. 88:2401-2411.

HAFEZ, B.; HAFEZ, E.S.E. Reprodução Animal. In: HAFEZ, B.; HAFEZ, E.S.E. In: Fisiologia da Reprodução. 7. ed. Barueri: Manole, 2004. Cap. 3, p. 33-53. 
JORRITSMA, R. et. al. Metabolic changes in early lactation and impaireds reproductive performance in dairy cows. Veterinary Research, v. 34, p, 11-26, 2003.

KENDRICK, K.W; BAILET, T.L; GARST, A.S; PRYOR, A.W; AHMADZADEH, A.; AKERS, R.M.; EYESTONE, W.E.; PEARSON, R.E.\& GWAZDAUSKAS, F.C. Effects of energy balance on hormones, ovarian activity and recovered oocytes in lactating holstein cows using transvaginal follicular aspiration. Journal Dairy Science, v. 82, p. 1731-1740, 1999.

LAGO, E.P. et al. Efeito da condição corporal ao parto sobre alguns parâmetros do metabolismo energético, produção de leite e incidência de doenças no pós parto de vacas leiteiras. Revista Brasileira de Zootecnia. v. 30, n. 5, p. 1544-1549, 2001.

LINO, A. D. Efeitos da redução da duração do período seco ou de sua omissão sobre as performances das vacas leiteiras. Maringá, 2009. Universidade Estadual de Maringá. Disponível em < http://www.nupel.uem.br/modificacao-periodo-seco.pdf/. Acesso em: 01 de abril de 2013

LUCY, M.C; STAPLES, C.R; MICHEL, F.M; THATCHER, W.W. Energy balance e size and number of ovarian follicles detected by ultrasonography in early postpartum dairy cows. Journal of Dairy Science, v. 74, p. 473-482, 1991.

LUCY, M.C. Partição de nutrients e desempenho reprodutivo em vacas leiteiras. Uberlândia.2005. Palestra proverida no IX Curso Novos Enfoques na Produção e Reprodução de Bovinos, em Uberlândia, em 25/11/2005.

MARTIN, Ian. Caracterização morfo-funcional do útero de bovinos durante o ciclo estral. 2003, 27f. Dissertação (Mestrado em Reprodução Animal) - Faculdade de Medicina Veterinária e Zootecnia, Botucatu.

MEDEIROS, S.F.; MEDEIROS, M.M.W.Y. Modificação dos níveis de gonadotrofinas durante a vida produtiva. Revista Brasileira de Ginecologia e Obstetrícia, v. 29, p. 48-55, 2006.

PEZESHKI, A., J. MEHRZAD, G. R. GHORBANI, H. R. RAHMANI, R. J. COLLIER, AND C. BURVENICH. 2007. Effects of short dry periods on performance and metabolic status in Holstein dairy cows. Journal Dairy Science, 90:5531-5541.

RASTANI, RR, GRUMMER RR, BERTICS SJ, A. GUMEN, WILTBANK WC, MASHEK DG, E RICH MC. 2003. Efeitos de diferentes duração do período seco e prepartum pro.les metabólica do peri-parto e lactação gado secundária. Journal Dairy Science. 86 (Suppl. 1): 154

RASTANI, R. R., R. R. GRUMMER, S. J. BERTICS, A. GÜMEN, M. C. WILTBANK, D. G. Mashek, and M. C. Schwab. 2005. Reducing dry period length to simplify feeding transition cows: Milk production, energy balance, and metabolic profiles. Journal Dairy Science, 88:1004-1014

ROYAL, M. D., DARWASH, A. O., FLINT, A. P. E., WEBB, R., Woolliams, J. A. and Lamming, G. E.. 2000. Declining fertility in dairy cattle: Changes in traditional and endocrine parameters of fertility. Animal Science, 70:487-501.

SCARAMUZZI, R.J; CAMPBELL, B.A; DOWNING, J.A; KENDALL, N.R; KAHALID, M; GUTIÉRREZMUNOZ, M. A review of the effects of supplementary nutrition in the ewe on the concentrations of reproductive and metabolic hormones and the mechanisms that regulate folliculogenesis and ovulation rate. Reprod. Nutr. Dev, v. 46, p. 339-354, 2006.

SCHNEIDER, J.E. Energy balance and reproduction. Physiology \& Behavior, v. 81, p. 289$317,2004$. 
SMITH, M. C. A. and WALLACE, J. M.. 1998. Influence of early post partum ovulation on the reestablishment of pregnancy in multiparous and primiparous dairy cattle. Reproduction and Fertility Development, 10:207-216.

STAPLES, C. R., THATCHER, W. W. and CLARK, J. H.. 1990. Relationship between ovarian activity and energy status during the early postpartum period of high producing dairy cows. Journal Dairy Science, 73:938-947.

THATCHER, W. W. and WILCOX, C. J.. 1973. Postpartum estrus as an indicator of reproductive status in dairy cows. Journal Dairy Science, 56:608-610.

WEBB, R.; NICHOLAS, B.; CONG, J.G.; CAMPBEL, B.K.; GUTIERREZ C.G., GAVERICK, H.A.; ARMSTRONG D.G. Mechanism regulating follicular development and selection of the dominant follicle. Reproduction Suplement, v. 61, p. 71-90, 2003.

WEBB, R.; GARNSWORTHY, P.C.; GONG, J.G.; ARMSTRONG, D.G. Control of follicular growth: local interactions and nutritional influences. Journal of Animal Science, v. 82, 63-74, 2004.

ZULU, V.C.; NAKAO, T.; SAWAMUKAI, Y. Insulin-like grouth factor-1 as a possible hormonal mediator of nutritional regulation of reproduction in catle. Theriogenology. v. 64, p. 657-665, 2002. 